\title{
EM CONFORMIDADE COM O DIREITO FUNDAMENTAL À SAÚDE PREVISTO NA CONSTITUIÇÃO BRASILEIRA DE 1988, É POSSÍVEL EXIGIR DO ESTADO A PRESTAÇÃO DE FOSFOETANOLAMINA SINTÉTICA PARA PESSOAS COM CÂNCER?
}

\author{
Cleber Sanfelici Otero* \\ Eduardo Augusto de Souza Massarutti**
}

SUMÁRIO: Introdução; 2 A Saúde como Direito Integrante do Direito ao Mínimo para uma Vida Digna; 3 Direito ao Acesso Universal à Saúde e sua Limitação de Acordo com a Análise da Escassez de Recursos; 4 Existe um Direito Fundamental à Aquisição de Fosfoetanolamina Sintética em Face do Estado?; 5 Considerações Finais; Referências.

RESUMO: No artigo, a proteção à saúde é observada como um direito fundamental integrante do direito ao mínimo de recursos para uma vida digna, assegurado pela Constituição brasileira a título universal. Em razão da escassez de recursos públicos para a saúde, o direito de requerer o composto fosfoetanolamina sintética ao Poder Público é analisado, considerando que esta substância ainda não foi reconhecida pela Medicina como eficaz no tratamento do câncer e não passou por todos os testes exigidos pela Agência Nacional de Vigilância Sanitária (ANVISA) para aprovação e registro. Para atingir este objetivo, é realizada uma investigação na literatura jurídica, com o método de abordagem dedutivo e os métodos de procedimento sistemático e dialético.

PALAVRAS-CHAVE: Direito fundamental à saúde; Escassez; Fosfoetanolamina.

\section{BASED ON THE RIGHT TO HEALTH REGULATED IN THE 1988 BRAZILIAN CONSTITUTION, IS IT POSSIBLE TO DEMAND FROM THE GOVERNMENT SYNTHETIC PHOSPHOETHANOLAMINE FOR PEOPLE WITH CANCER?}

ABSTRACT: Health protection is a basic right to the minimum resources for a worthy life for all guaranteed by the Brazilian Constitution. Owing to scarcity of public

\footnotetext{
Doutor e Mestre em Direito pelo Programa de Pós-graduação Stricto sensu Sistema Constitucional de Garantia de Direitos da Instituição Toledo de Ensino, (ITE), Bauru (SP); Docente no Curso de Graduação em Direito e no Programa de Pós-Graduação em Ciências Jurídicas do Centro Universitário de Maringá (UNICESUMAR), Maringá (PR), Brasil; Docente no Curso de Especialização em Direito Previdenciário da Universidade Estadual de Londrina (UEL), Londrina (PR); Pesquisador pelo ICETI; Juiz Federal; E-mail: cleber.otero@unicesumar. edu.br

** Mestre pelo Programa de Pós-Graduação em Ciências Jurídicas do Centro Universitário de Maringá (UNICESUMAR), Maringá (PR), Brasil; Docente na Faculdade Cidade Verde (FCV), Maringá (PR), Brasil; Advogado.
} 
funds in health, the right to demand phosphoethanolamine from the government is discussed. The compound has not been acknowledged by the medical community as an efficacious drug against cancer since it never followed all the tests required by the Brazilian National Agency in Health Vigilance (ANVISA) for approval and medical registration. The judicial literature is investigated by deductive methodology coupled to systematic and dialectic procedures.

KEY WORDS: Basic right to health; Scarcity; Phosphoethanolamin.

\section{DE ACUERDO CON EL DERECHO FUNDAMENTAL A LA SALUD PREVISTO EN LA CONSTITUCIÓN BRASILEÑA DE 1988, ¿ES POSIBLE EXIGIR AL ESTADO LA DISPOSICIÓN DE FOSFOETANOLAMINA SINTÉTICO PARA PERSONAS CON CÁNCER?}

RESUMEN: En el artículo, la protección de la salud es vista como un derecho fundamental a los recursos mínimos para una vida digna, garantizado por la Constitución brasileña a título universal. Dada la escasez de recursos públicos para la salud, se analiza el derecho de aplicar la fosfoetanolamina sintético hecho al Gobierno, teniendo en cuenta que esta sustancia no ha sido reconocido por la medicina tan eficaz en el tratamiento del cáncer y no ha pasado todas las pruebas requeridas por Agencia nacional de Vigilancia Sanitaria (ANVISA) para su aprobación y registro. Para lograr este objetivo, la investigación se lleva a cabo en la literatura jurídica, con el método deductivo de enfoque y los métodos de procedimiento sistemático y de dialéctica.

PALABRAS-CLAVE: Derecho fundamental a la salud; La escasez; Fosfoetanolamina.

\section{INTRODUÇÃO}

A partir da publicação da Constituição Federal de 1988, nos termos dos arts. $6^{\circ}$ e 196 e seguintes, a saúde foi inserida no texto constitucional como um direito social e passou a ser considerada direito de todos e dever do Estado, o qual assumiu a obrigação de assegurá-la por meio de políticas públicas que objetivem a diminuição do risco de doença e de outros agravos, além do acesso universal e igualitário às ações e serviços para sua promoção, proteção e recuperação. 
A saúde é um direito fundamental que guarda relação com o pleno desenvolvimento da personalidade humana e integra o direito ao mínimo para uma vida digna, conforme o princípio da dignidade da pessoa humana, também previsto na Constituição Federal brasileira.

Os direitos fundamentais podem sofrer limitações, conforme se constata na teoria geral dos direitos fundamentais, na medida em que eles não são absolutos e porque os recursos utilizados para concretização de direitos não são infinitos.

Sob o pressuposto de que a Constituição Federal brasileira assegura o acesso universal e igualitário para promoção, proteção e recuperação da saúde, considerando que ela é um direito fundamental e integrante do direito ao mínimo para uma vida digna, bem como as recentes discussões a respeito da utilização da fosfoetanolamina, o presente estudo tem como objetivo principal verificar se o Poder Público tem o dever constitucional de disponibilizar gratuitamente a substância em face da existência do direito fundamental, apesar do caráter experimental acerca da eficácia do composto químico.

A análise do tema revela-se de extrema relevância, uma vez que a saúde passou a ser considerada um direito fundamental no Brasil e a aquisição gratuita de medicamentos faz parte deste direito. $\mathrm{E}$, mesmo que não estivesse prevista na Constituição Federal com este caráter, a importância de sua análise seria evidente, na medida em que a vida, a integridade física e a psíquica fazem parte da personalidade do ser e o desrespeito à saúde atinge esses bens fundamentais e a dignidade da pessoa humana. Outrossim, a fosfoetanolamina ainda é considerada uma substância experimental quanto à eficácia medicinal, razão pela qual não se pode precisar com segurança os seus efeitos colaterais, o que implica a questão de saber se, nestes casos, o Estado estaria obrigado a arcar com os custos de distribuição por meio do Sistema Único de Saúde (SUS).

Para concretização do objeto proposto, será utilizado o método de investigação bibliográfico, por meio da análise da literatura nacional e estrangeira a respeito dos direitos fundamentais e do direito à saúde, além de artigos recentes sobre o uso e disponibilização da fosfoetanolamina. O método de abordagem dedutivo é empregado para verificar, a partir das normas do ordenamento jurídico brasileiro, se há a compreensão do custo do direito à saúde em face das necessidades sociais e das pessoas que procuram o sistema de saúde. Por fim, os métodos de procedimento sistemático e dialético são usados para promover uma discussão acerca do contexto 
da necessidade das pessoas de proteção ao bem jurídico fundamental da saúde em detrimento da dificuldade de obtenção de recursos para tratamentos médicos, da realização de exames em razão do avanço tecnológico na área da Medicina e a respeito do caráter científico-experimental da fosfoetanolamina e dos seus possíveis efeitos colaterais.

\section{A SAÚDE COMO DIREITO INTEGRANTE DO DIREITO AO MÍNIMO PARA UMA VIDA DIGNA}

Para o homem, não é possível existir bem mais precioso do que a própria pessoa humana. O ser humano, por duas particularidades naturais, possuidor de inteligência, consciência e vontade, por não ser apenas uma fatia de matéria, possui uma dignidade que o distingue dos demais seres e das coisas naturais. Até as teorias denominadas materialistas, as quais não admitem a espiritualidade do ser humano, sempre foram impulsionadas a admitir que existe uma parte não material na pessoa humana. Há uma dignidade pertinente à condição humana, e a manutenção dessa dignidade integra os direitos humanos. ${ }^{01}$

Independente da distinção, a ideia de direitos humanos, direitos do homem ou direitos fundamentais está ligada à noção de dignidade da pessoa humana. O homem, como ser distinto dos demais seres, possui uma dignidade que lhe é peculiar, uma noção de pessoa em si mesmo e em relação ao outro, conhecimento este que o faz diferente de todas as demais criaturas que existem.

O surgimento da consciência histórica dos direitos humanos somente se verificou depois de um extenso trabalho preparatório, focado em volta da restrição do poder político. A admissão de que as organizações governamentais devem ser usufruídas para bem dos governados - e não em beneficio próprio daqueles que estão no poder - foi um primeiro passo definitivo no reconhecimento da existência de direitos que devem ser acessados por todos, e não apenas como liberalidade dos governantes. ${ }^{02}$

No século XVII, a noção de direitos naturais não disponíveis do homem e da submissão da autoridade às regras do direito natural alcançou voz nas obras do holandês Hugo Grócio (1583-1645), do alemão Samuel Pufendorf (1632-1694) e dos

\footnotetext{
${ }^{01}$ DALLARI, Dalmo de Abreu. Direitos humanos e cidadania. 2. ed. São Paulo: Moderna, 2004, p. 15.

${ }^{02}$ SARLET, Ingo Wolfgang. A eficácia dos direitos fundamentais: uma teoria geral dos direitos fundamentais na perspectiva constitucional. 12. ed.. Porto Alegre: Livraria do Advogado, 2015, p. 53.
} 
ingleses John Milton (1608-1674) e Thomas Hobbes (1588-1679). Milton buscou o reconhecimento dos direitos de autodeterminação do ser humano, de aceitação religiosa, da liberdade de comunicação oral e de imprensa, além da extinção da censura, ao passo que Hobbes conferiu ter o homem alguns direitos naturais, mas que atingiam validade apenas no estado da natureza, achando-se, no mais, ao dispor do soberano. ${ }^{03}$

A Declaração de Direitos do Povo da Virgínia de 1776 foi o documento histórico que evidenciou a existência dos direitos fundamentais como inerentes ao homem, conforme consta em seu artigo primeiro: "Que todos os homens são, por natureza, igualmente livres e independentes, e têm certos direitos inatos, dos quais, quando entram em estado de sociedade, não podem por qualquer acordo privar ou despojar seus pósteros [...].”4

Em um primeiro momento, a proteção das pessoas restou reconhecida internamente nos Estados como direito fundamental, mas, em tempos mais recentes, o reconhecimento de direitos das pessoas passou a ocorrer também no plano internacional.

Antonio Enrique Pérez Luño esclarece que a expressão direitos fundamentais é utilizada para denominar os direitos positivos no âmbito interno, enquanto que direitos humanos seria mais empregada para designar os direitos naturais positivados em declarações e convenções internacionais, bem como aquelas obrigações relacionadas com a dignidade humana, liberdade e igualdade da pessoa que não alcançou um estatuto jurídico positivo. ${ }^{05}$

A partir de 1945, os horrores perpetrados pela Segunda Guerra Mundial vieram a aprofundar a afirmação histórica da dignidade humana e dos direitos humanos, sendo que o documento que estabeleceu acentuadamente essa nova etapa histórica foi a Declaração Universal dos Direitos do Homem, aprovada em 1948, com a subsequente internacionalização dos direitos humanos por meio de diversas convenções aprovadas perante a Organização das Nações Unidas (ONU) e a Organização Internacional do Trabalho (OIT). ${ }^{06}$

${ }^{03}$ Ibid., p. 39.

${ }^{04}$ ESTADOS UNIDOS DA AMÉRICA. Declaração de Direitos do Bom Povo de Virgínia. [Universidade de São Paulo - USP. Biblioteca virtual de direitos humanos]. Disponível em: <http://www.direitoshumanos.usp.br/ index.php/Documentos-anteriores-\%C3\%A0-cria\%C3\%A7\%C3\%A3o-da-Sociedade-das-Na\%C3\%A7\%C3\%B5es -at\%C3\%A9-1919/declaracao-de-direitos-do-bom-povo-de-virginia-1776.html> . Acesso em: 14 jan. 2016.

${ }^{05}$ PÉREZ LUÑO, Antonio Henrique. Los derechos fundamentales: temas clave de la Constituición española. 11. ed. Madrid: Tecnos, 2013, p. 39-40.

${ }^{06}$ COMPARATO, Fábio Konder. A afirmação histórica dos direitos humanos. 9. ed. São Paulo: Saraiva, 2015 p. 68-69. 
Dentre os direitos fundamentais mais caros para o ser humano encontra-se a saúde, especialmente pelo fato de estar diretamente relacionada com a dignidade da pessoa humana e os direitos da personalidade (direito à vida, à integridade física e psíquica, etc.). A propósito, não apenas direitos civis, mas vários direitos sociais foram reconhecidos na Declaração Universal dos Direitos Humanos, em seu artigo $\mathrm{XXV}$, como decorrentes do direito humano a um padrão de vida suficiente para uma vida digna, dentre eles o direito à saúde, ao bem-estar e a cuidados médicos. ${ }^{07}$ No mesmo rumo, o artigo 12 do Pacto Internacional sobre os Direitos Econômicos, Sociais e Culturais (PIDESC) de 1966, que dispôs acerca do "direito de toda pessoa de desfrutar o mais elevado nível possível de saúde física e mental". 08

Internamente, nos Estados, por ser um direito de âmbito coletivo, a saúde faz parte dos direitos de segunda geração/dimensão, que englobam os direitos sociais, culturais e econômicos, além dos direitos coletivos ou de coletividades, inseridos no constitucionalismo das diferentes formas de Estado Social, após terem nascido por meio da ideologia e do pensamento antiliberal do século XX e vinculados diretamente ao princípio da igualdade.$^{09}$ Como os direitos de liberdade não foram suficientes para assegurar a proteção das pessoas, o Estado passou a intervir a fim de impor limites ao abuso econômico e à exploração das pessoas no trabalho e em outros aspectos sociais, inclusive assumindo a prestação de benefícios para assegurar as pessoas em face de contingências que poderiam vir a sofrer.

Os direitos sociais conferem a noção de ser fundamental para proteger o indivíduo, já segundo acontecia no pensamento clássico dos direitos de liberdade, mas agora com a salvaguarda da instituição, um fato social muito mais rico e receptivo à participação criativa e à valorização da personalidade que o pano de fundo clássico da solidão individual, no qual nascera a exaltação do homem não concreto e isolado, sem a intensidade dos valores existenciais, os únicos efetivados de maneira plena pelo social. ${ }^{10}$

${ }^{07}$ OTERO, Cleber Sanfelici. Inclusão social da extrema pobreza: direito à cidadania integral e contextualização do mínimo necessário no Brasil. 2011. 444 f. Tese (Doutorado em Direito) - Instituição Toledo de Ensino de Bauru, Bauru.

${ }^{08}$ ORGANIZAÇÃO DAS NAÇÕES UNIDAS (ONU). Assembleia-Geral das Nações Unidas. Pacto Internacional sobre os Direitos Econômicos, Sociais e Culturais. Nova York, em 19 de dezembro de 1966. Resolução ${ }^{\circ}$ 2200-A (XXI). Disponível em: < http://pfdc.pgr.mpf.gov.br/atuacao-e-conteudos-de-apoio/legislacao/direitos -humanos/pacto_int_dir_econ_sociais-culturais.pdf>. Acesso em: 19 set. 2016. O PIDESC entrou em vigor na ordem internacional apenas em 3 de janeiro de 1976, foi ratificado pelo Brasil em 24 de janeiro de $1992 \mathrm{e}$ promulgado por meio do Decreto $\mathrm{n}^{\circ}$ 591, de 6 de julho de 1992.

${ }_{09}$ BONAVIDES, Paulo. Curso de Direito Constitucional. 29. ed. São Paulo: Malheiros, 2014, p. 578.

${ }^{10}$ Ibid., p. 579. 
A saúde é um valor indispensável do e ao ser humano, motivo pelo qual também é um direito fundamental e da personalidade, o qual, mesmo se não houvesse regra expressa para reconhecê-lo, já seria digno de proteção pelo Direito, porquanto afeto à qualidade de direito individual ou político. ${ }^{11}$ Portanto, a proteção à saúde, antes de ser um direito social, não deixa de ser também um direito individual.

O direito à saúde compõe-se, com muito mais importância, na condição de um direito peculiar de personalidade relacionado ao direito à qualidade de vida. $\mathrm{A}$ vida deve ser gozada com um mínimo de qualidade e, na ausência de saúde, esta qualidade se extingue, razões pelas quais o direito à saúde se apresenta como um direito especial de personalidade. ${ }^{12}$

Esse direito pertence a um grupo denominado de direitos sociais da personalidade, no qual se inclui também o direito ao trabalho, à informação, ao lazer, ao silêncio, à moradia. ${ }^{13}$

Por outro lado, a saúde não é apenas um direito fundamental ou da personalidade, mas integra o que a doutrina costuma chamar de direito ao mínimo para uma vida digna.

A dignidade da pessoa humana necessita de um mínimo de condições para que seja respeitada, o qual não pode ser confundido com meros recursos suficientes para a subsistência do individuo, a exemplo de algumas refeições diárias que permitam que a pessoa sobreviva, ausência de danos físicos etc. A vida digna necessita de recursos materiais e imateriais. ${ }^{14}$

O mínimo existencial guarda relação com o conjunto de ocorrências materiais fundamentais à vida humana digna, não somente como experiência física, mas também espiritual e intelectual, aspectos indispensáveis em um Estado que se intitula, de um lado, democrático, requerendo a participação dos indivíduos nas decisões públicas, e, de outro, liberal, deixando na responsabilidade de cada um seu próprio desenvolvimento. ${ }^{15}$

${ }^{11}$ PASOLD, Cesar Luiz. Direito à Saúde. Universidade Federal de Santa Catarina. Disponível em: < https://periodicos.ufsc.br/index.php/sequencia/article/view/16398/14978 > . Acesso em: 01 fev. 16.

${ }^{12}$ SZANIAWSKI, Elimar. Direitos de personalidade e sua tutela. 2. ed. São Paulo: Revista dos Tribunais, 2005, p. 170.

${ }^{13}$ SOUZA, Sérgio Iglesias Nunes. Responsabilidade civil por danos à personalidade. Barueri, SP: Manole, 2002, p. 7.

${ }^{14}$ BITENCOURT, Eurico Neto. O direito ao mínimo para uma existência digna. Porto Alegre: Livraria do Advogado, 2010, p. 118.

15 BARCELLOS, Ana Paula. Eficácia jurídica dos princípios constitucionais: o princípio da dignidade da pessoa humana. 3. ed. Rio de Janeiro: Renovar, 2011, p. 247. 
O mero tratamento não degradante ou a proteção da integridade física não são suficientes para que seja assegurado o respeito à dignidade da pessoa humana. ${ }^{16}$

Nesse sentido, a saúde, por ser um dos bens mais caros para o ser humano, está entre aqueles que fazem parte do mínimo para uma vida digna. Até porque uma saúde em condições precárias e sem os recursos necessários para o seu restabelecimento implicará consequências graves para o indivíduo, com sérios riscos de extinção da própria vida, capazes de atingir diretamente sua dignidade.

Sem a devida proteção à saúde por parte do Direito e dos responsáveis pela sua concretização, não há que se falar em dignidade ou na existência de uma vida digna. Sem dúvida, a saúde é um bem material e imaterial para o qual o Estado e a sociedade não podem deixar de oferecer proteção, sob pena de séria afronta à dignidade da pessoa humana.

\section{DIREITO AO ACESSO UNIVERSAL À SAÚDE E SUA LIMITAÇÃO DE ACORDO COM A ANÁLISE DA ESCASSEZ DE RECURSOS}

A Constituição da República Federativa do Brasil estabelece, em seu art. 196, que: "A saúde é direito de todos e dever do Estado, garantido mediante políticas públicas sociais e econômicas que visem à redução do risco de doença e de outros agravos e ao acesso universal igualitário às ações e serviços para sua promoção, proteção e recuperação". ${ }^{17}$

Percebe-se que a referida norma agregou, a título de direito dos brasileiros, o conceito do direito à saúde e o ingresso estendido às ações de saúde, as quais não se limitam aos cuidados de doentes, ou seja, a descoberta inicial e o tratamento a fim de que eles se reabilitem. Vai além, pois busca suprir as carências da saúde, no intuito de aumentá-la por meio da promoção da saúde, como acontece no caso da assistência à gestante, da prevenção de doenças (proteção específica), como se verifica nos sistemas de vacinação no primeiro ano de vida, e da reabilitação da capacidade daqueles que suportaram danos físicos ou doenças no passado, como ocorre com os programas para hansenianos. ${ }^{18}$

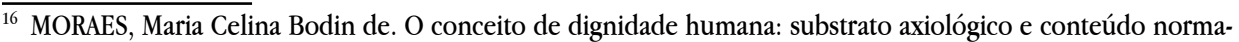
tivo. In: SARLET, Ingo Wolfgang (Org.). Constituição, direitos fundamentais e direito privado. 3. ed. Porto Alegre: Livraria do Advogado, 2010, p. 119.

${ }^{17}$ BRASIL. Constituição (1988) Constituição da República Federativa do Brasil: promulgada em 5 de outubro de 1988. São Paulo: Saraiva, 2014, p. 138.

${ }^{18}$ ROCHA, Juan Stuardo Yazlle. População e serviços de saúde: as necessidades, demanda e utilização de serviços. In: ROCHA, Juan Stuardo Yazlle. Manual de saúde pública \& saúde coletiva no Brasil. São Paulo: Atheneu, 2012, p. 43-44.
} 
Mesmo diante de um sistema de saúde considerado moderno e de políticas públicas para promoção, proteção e recuperação da saúde da população brasileira, o cotidiano revela uma realidade que não condiz com o direito previsto pela Constituição Federal. Nem todo mundo consegue ser atendido ou usufruir dos serviços de saúde, porquanto, em boa parte dos casos, desistem ante a ausência de vagas, grande tempo de espera, etc. ${ }^{19}$

O crescimento no número de demandas judiciais também demonstra que as ações em saúde por meio de seu sistema único não têm sido eficazes para atender a todas as necessidades daqueles que se encontram com a saúde debilitada. $\mathrm{O}$ aumento no ajuizamento de ações judiciais se fez notar principalmente após decisão do Supremo Tribunal Federal (STF) na Suspensão de Tutela Antecipada (STA) n. 175, julgada em 10/03/2010, em que reconheceu a responsabilidade estatal (de todos os entes federativos, inclusive de forma solidária) ao fornecimento de medicamentos, não como decorrência de judicialização da matéria, mas muito mais pela ausência da observância de políticas públicas existentes. ${ }^{20}$ No julgado em Plenário do Agravo Regimental na referida STA, restou claro que o Estado não está obrigado a fornecer remédios não testados ou em fase experimental, nem remédios mais caros, mas poderá fornecer remédio importado se for constatada a eficácia de uma nova composição, ainda que o tratamento não seja reconhecido pela ANVISA. ${ }^{21}$

Um balanço, que estava sendo concluído pelo Conselho Nacional de Justiça (CNJ) em 2011, já revelava a tramitação de 240.980 demandas judiciais na área de saúde, as denominadas demandas judiciais da saúde, a maioria relacionadas a reclamações de pessoas que buscavam acesso a medicamentos e a eventos médicos por meio do SUS, além de vagas em nosocômios públicos e outras ações relacionadas a seguros e planos privados. ${ }^{22}$

Diversos fatores apontam para o fato de que a saúde no Brasil não vem recebendo o tratamento adequado e, consequentemente, a garantia constitucional

19 Ibid., p. 45.

${ }^{20}$ SILVA, Diogo Bacha e; GONÇALVES, Luciano Meni. Judicialização da saúde e a transferência do controle sobre o corpo. Revista Jurídica Cesumar - Mestrado. Maringá, PR, v. 13, n. 2, p. 561-579, jul./dez. 2013. Disponível em: <http://periodicos.unicesumar.edu.br/index.php/revjuridica/article/view/3047/2139>. Acesso em: 19 set. 2016.

21 RODRIGUES, Okçana Yuri Bueno; OTERO, Cleber Sanfelici. Comentários a acórdão do Supremo Tribbunal Federal em Agravo Regimental que manteve tutela antecipada concessória de medicamentos em nome da preservação do direito à saúde. Revista Jurídica Cesumar - Mestrado. Maringá, PR, v. 13, n. 2, p. 743-759, jul./dez. 2013. Disponível em: < http://periodicos.unicesumar.edu.br/index.php/revjuridica/article/view/3099/2147>. Acesso em: 19 set. 2016.

22 BRASIL. Conselho Nacional de Justiça. Disponível em: <http://www.cnj.jus.br/noticias/ cnj/56636-brasil-tem-mais-de-240-mil-processos-na-area-de-saude.> Acesso em: 12 jan. 2016. 
de direito de acesso universal e igualitário à saúde não se tem concretizado na prática.

O Estado Democrático de Direito e Social, modelo atual, apresenta-se como ente garantidor de recursos mínimos para uma vida digna. A ele não basta prever direitos, ainda que inseridos na Constituição Federal, mas deve ir além, criando políticas públicas, as quais devem ser concretizadas por meio de programas eficazes. Porém, o Estado brasileiro, por meio de seus órgãos governamentais tem lançado do principio da "reserva do possível." 23

Direitos com características prestacionais estão atrelados à existência de recursos ou à uma reserva do materialmente possível, porém o direito ao mínimo para uma vida digna não se relaciona a este limite, uma vez que a dignidade da pessoa humana implica necessariamente que o Estado, de forma primordial, garanta meios indispensáveis para uma existência digna. ${ }^{24}$

É certo afirmar que assegurar recursos materiais fundamentais à dignidade humana (o mínimo existencial) é a primazia do Estado brasileiro. Essa prioridade deverá impactar o modo como são disponibilizados os recursos públicos, os quais deverão ser direcionados para assegurar condições materiais indispensáveis à uma vida digna. Assim, o embate a respeito da reserva do possível sequer deveria ser importante nesse âmbito, uma vez que se está protegendo a prioridade número um, a não ser que não haja até mesmo condições suficientes para atender aquilo que se considera o mínimo existencial. ${ }^{25}$

A dignidade humana atua como limite dos limites dos direitos fundamentais, no viés de que qualquer restrição nunca poderá excluir o princípio diretor do sistema de direitos fundamentais ${ }^{26}$, por ser a dignidade o fundamento nuclear de cada um dos direitos fundamentais, que não pode ser desprezado em essência, sob pena de os direitos serem negligenciados em seu mínimo.

Com efeito, a vida digna possui um núcleo dentro do princípio da dignidade humana, que é o mínimo de condições ou instrumentos assecuratórios para uma

\footnotetext{
${ }^{23}$ BARCELLOS, Ana Paula. Eficácia jurídica dos princípios constitucionais: o princípio da dignidade da pessoa humana. 3. ed. Rio de Janeiro: Renovar, 2011, p. 277. De forma geral, a expressão reserva do possível procura identificar o fenômeno econômico da limitação dos recursos disponíveis diante das necessidades quase sempre infinitas a serem por eles supridas. [...] a reserva do possível significa que, para além das discussões jurídicas sobre o que se pode exigir judicialmente do Estado - e em última análise da sociedade, já que é esta que o sustenta -, é importante lembra que há um limite de possibilidades materiais para esses direitos.

${ }^{24}$ BITENCOURT, Eurico Neto. O direito ao mínimo para uma existência digna. Porto Alegre: Livraria do Advogado, 2010, p. 131.

${ }^{25}$ BARCELLOS, op. cit., p. 288.

${ }^{26}$ FREITAS, Luiz Fernando Calil. Direitos fundamentais: limites e restrições. Porto Alegre: Livraria do Advogado, 2007, p. 220-221.
} 
existência com dignidade, o qual não pode ser afetado em nenhuma hipótese. Se o administrador público ou o legislador tiver que fazer uma escolha entre direitos fundamentais a serem concretizados, ele até poderá realizar esta opção com supedâneo na cláusula da reserva do possível, mas jamais estará autorizado a atingir o mínimo capaz de proporcionar uma existência digna.

Nesse sentido, pelo menos do ponto de vista teórico, a saúde, como parte integrante de um mínimo de recursos necessários para uma existência digna não poderia sofrer qualquer tipo de restrição, até porque a dignidade da pessoa humana vem prevista logo no art. $1^{\mathrm{o}}$, inciso III, da Constituição brasileira, como fundamento do Estado Democrático de Direito.

Apesar da proteção conferida ao direito à saúde, é preciso levar em consideração que o número de habitantes do Brasil aumentou drasticamente nas últimas décadas, a população envelheceu, bem como que houve um grande desenvolvimento da indústria e da tecnologia, especialmente na área da saúde. Esse crescimento também ocorreu de forma significativa após a Constituição de 1988 e houve também um aumento significativo de novas patologias.

O progresso do conhecimento científico possibilitou o nascimento de equipamentos para efetivação de exames de imagem, até então não pensados, há pouco mais de 50 anos. Aparelhos de tomografia, ultrassonografia e ressonância magnética, conquanto tenham contribuído para melhoria da precisão dos diagnósticos, também impulsionaram o aumento dos custos dos eventos de saúde em todo o mundo. ${ }^{27}$

A implantação de novas tecnologias na área de saúde é distinta, porque acontece de maneira cumulativa com outras já ratificadas pelo uso. Dessa forma, um dano em membro superior ou inferior poderá ser diagnosticado com o uso da radiografia já conhecida há muitos anos, mas acrescentada da realização de ressonância magnética, que é uma ferramenta mais atual. O profissional poderá determinar a realização de ambas para inferir seu diagnóstico e, a priori, não poderá ser questionado, apesar de o custo ser mais elevado. ${ }^{28}$

Em sociedades contemporâneas, que possuem como caráter principal o consumo exagerado, principalmente por novidades da tecnologia, a área da saúde não conseguiu fugir do apelo consumista, também. ${ }^{29}$

\footnotetext{
${ }^{27}$ CARLINI, Angélica Lúcia. Judicialização da saúde pública no Brasil. In: CARNEIRO, Luiz Augusto Ferreira (Coord). Planos de saúde: aspectos jurídicos e econômicos. Rio de Janeiro: Forense, Gen, IESS, 2012, p. 24.

${ }^{28}$ Ibid., p. 25.

${ }^{29}$ Id.
} 
É necessário admitir que os custos com a saúde são elevados e que, no Brasil, e provavelmente em vários países, os recursos financeiros não são suficientes para atender a toda a população que procura os serviços de saúde, fato a implicar a necessidade de uma análise econômica da saúde.

Supostamente, economia e saúde são esferas do conhecimento que não se comunicam. A imaginação popular crê que, quando se refere à saúde, todos os recursos financeiros devem ser aplicados, uma vez que a vida não tem valor econômico. E, por ser o valor fundamental de existência, realmente não tem, embora haja custos para mantê-la, cada vez mais elevados, em uma nação assinalada pela forte utilização de tecnologia em todos os seguimentos, principalmente o da saúde. $^{30}$

Nos últimos anos, os sistemas de saúde de várias nações têm sido questionados se atingem suficientemente o que seus usuários estão esperando. ${ }^{31}$

Até as nações mais ricas não conseguem atender, de uma só vez, todas as necessidades e anseios da população, de forma que os utilizadores do setor de saúde terão lançar mão de gastos complementares, os quais serão mais altos quanto mais exíguos forem os recursos. ${ }^{32}$

É relevante reforçar que as alterações e melhorias na área de tecnologia de outros setores da economia atingem o sistema de saúde. Por exemplo, um ensino de melhor qualidade, um sistema de transmissão de dados que seja adequado às necessidades e a facilidade no acesso aos meios de transporte possibilitam que mais pessoas consigam aumentar o acesso ao sistema de saúde e serem salvas. ${ }^{33}$

A própria Organização Mundial da Saúde (OMS) tem percebido a relevância das consequências econômicas da má saúde e da doença, das restrições financeiras que, com frequência, vão contra a disponibilização de assistência médica e sanitária correta e dos obstáculos à análise dos benefícios decorrentes dessa assistência, em termos monetários ou em referência a outros requisitos. ${ }^{34}$

Os custos com a assistência à saúde estão crescendo tanto nas nações desenvolvidas como também nos países em desenvolvimento e também nos

\footnotetext{
${ }^{30}$ Ibid., p. 30. Atlas, 2010, p. 128. MedBook, 2013, p. 566.

33 FERRAZ, op. cit., p. 128.

34 SILVA, op. cit, p. 559.
}

${ }^{31}$ FERRAZ, Marcos Bosi. Economia da saúde e sua inserção no sistema da saúde. In: BLIACHERIENE, Ana Carla; SANTOS, José Sebastião dos (Org.). Direito à vida e à saúde: impactos orçamentários e judicial. Sâo Paulo,

32 SILVA, Marcelo Gurgel Carlos da. Econômica da saúde: da epidemiologia à tomada de decisão. In: ROUQUAYROL, Maria Zélia; SILVA, Marcelo Gurgel Carlos da (Org.). Epidemiologia \& Saúde. 7. ed. Rio de Janeiro: 
subdesenvolvidos. Para ser ter uma ideia mais clara, em 1990, o gasto global com saúde atingiu a quantia de US\$1,7 trilhão, ou, aproximadamente, $8 \%$ da remuneração mundial. ${ }^{35}$

Diante deste panorama, como aliar esperanças de prováveis usuários desses sistemas de saúde com a riqueza à disposição atualmente, em um espaço exageradamente complicado, que é o sistema de saúde, e em periódica e acelerada alteração, pelos motivos já expostos? Noutros termos, como estabelecer e combinar a assistência à saúde, conforme três aspectos: qualidade, acesso e custo? A própria conceituação de qualidade e acesso já implica um desafio, mas, admitindo-se que seja possível tal definição, surge o seguinte problema: disponibilizar acesso capaz de satisfazer as necessidades com o mínimo de limitação possível e com o máximo de custo tolerável por essa sociedade. ${ }^{36}$

A meta hodierna é aliar a expectativa do usuário e aquilo que é necessário para ele, com as provisões disponíveis e distribuídas para o sistema de saúde. Entretanto, é evidente também que existe uma restrição econômica nesse processo. ${ }^{37}$

Por existir essa limitação, tornou-se necessária uma análise econômica da saúde, o que tem sido feito por meio de ferramentas validadas e hoje disponíveis, quais sejam, a epidemiologia clínica (busca utilizar os melhores métodos de pesquisa e a melhor evidência disponível para o paciente certo) ou a assistência à saúde baseada em evidência e economia da saúde. ${ }^{38}$

O exame da economia da saúde é relevante e chama a atenção por três motivos: a) pelas extensões da colaboração da área de saúde para o total da economia; b) pelas inquietações com as políticas nacionais, em razão da relevância que muitas pessoas dão aos problemas econômicos que com os quais se deparam ao buscar conseguir e manter sua própria saúde; e (c) em face da quantidade de problemas de saúde, munidos de um conteúdo econômico substancioso. ${ }^{39}$

Em razão de observar processos biológicos, as previsões dos acontecimentos em análise e inseridos no estudo econômico em saúde são, por sua característica, incertos. Por esse motivo, apenas com a utilização criteriosa dos instrumentos disponíveis é que se verificará aptidão para a realização de escolhas que unam a ciência a uma melhor utilidade pelo sistema dos finitos meios à disposição. ${ }^{40}$

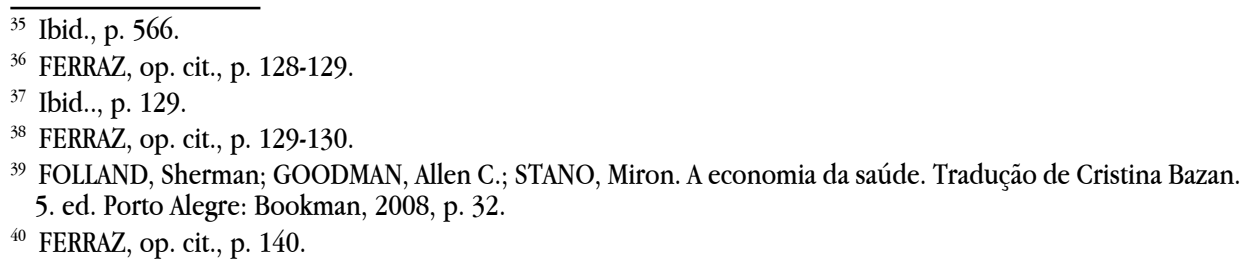


No caso do Brasil, a situação é ainda mais grave quando se pensa em recursos para atender ao setor de saúde. Além da não destinação dos recursos, do desvio e da sua má aplicação, a quantia disponibilizada com saúde está bem aquém do que é recomendado pela Organização Mundial da Saúde, a ponto de investir menos em saúde do que países mais pobres que o Brasil. ${ }^{41}$

A concretização dos direitos a prestações positivas exige disponibilidade de recursos financeiros, como é o caso do direito à saúde, à aposentadoria, à moradia, à educação, estes os mais evidentes. Por isso, a quantidade de sua implantação com maior ou menor força oscila de acordo a existência de recursos disponíveis para tais destinações e usos. ${ }^{42}$

Apesar destas ponderações e o posicionamento na direção de que a reserva do possível se estabelece como limite fático aos direitos fundamentais prestacionais, é preciso considerar que os direitos sociais possuem uma substância nuclear portadora de especial intensidade jurídica motivada pela vinculação instantânea à ideia de dignidade da pessoa humana, razão pela qual mereceria ponderação a utilização da reserva do possível enquanto restringente dos direitos fundamentais. Afinal, nenhum outro princípio, dotado da mesma força da dignidade da pessoa humana, poderia justificar, a qualquer custo e em todo e qualquer contexto, a vinculação não vantajosa de direitos fundamentais, por meio dos quais também se procura concretizar a dignidade humana. ${ }^{43}$

Ingo Wolfgang Sarlet chega a afirmar que a existência de uma restrição fática imposta pela reserva do possível e um restringente jurídico que decorre da reserva parlamentar referente ao conteúdo orçamentário relativizam a eficácia e a concretização dos direitos fundamentais prestacionais sociais. A ausência de recursos econômicos públicos não pode, todavia, significar que, perante prestações a implicar necessidades emergenciais cujo indeferimento judicial acarrete o fim do direito à vida, à saúde, à integridade física e à dignidade da pessoa humana, haja o enfraquecimento ou extinção do direito subjetivo do ser humano à proteção prevista na Constituição. ${ }^{44}$

Para Michel Foucault, ao se avocarem os problemas relacionados ao campo da saúde, adentra-se numa sequência de valores que abre espaço a uma "demanda

$\overline{41}$ SILVA, op. cit., p. 581.

${ }^{42}$ FREITAS, op. cit., p. 173.

${ }^{43}$ Ibid., p. 174-175.

${ }^{44}$ SARLET, Ingo Wolfgang. Algumas considerações entorno do conteúdo, eficácia e efetividade do direito à saúde na constituição de 1988. Revista Diálogo Jurídico. Salvador: CAJ - Centro de Atualização Jurídica, n. 10, jan. 2002. Disponível em: < http://www.direitopublico.com.br>. Acesso em: 28 jan. 16. 
infinita", sobrando o problema constante de como combinar esta "demanda infinita com um sistema finito". Os instrumentos de que uma sociedade pode dispor para responder às suas demandas estarão sempre aquém de duas próprias necessidades. ${ }^{45}$

Assim, o direito, a decisão a respeito do que deve ser o fim de sua atividade, a determinação de suas estruturas formais, o estabelecimento dos instrumentos efetivos de sua aplicação não são de responsabilidade única do Estado, pois não compete somente aos governantes dedicar-se ao direito, já que a responsabilidade seria de todos os indivíduos. ${ }^{46}$

Em razão disso, seria possível aceitar a ideia do bioeticista espanhol Diego Gracia ao julgar que deve ser reformulada a máxima: "A cada pessoa conforme as suas necessidades", transformando-a em: "A cada pessoa conforme suas necessidades até o limite que permitam os bens disponíveis". Dessa forma, ainda que se esteja diante de um sistema do tipo universalista, seria adequado restringir, por ausência de recursos, alguns eventos médicos e ações de saúde para todos. ${ }^{47}$

Como preservar um justo fornecimento? Quais os fundamentos éticos norteadores da disponibilização de prioridades para as políticas sanitárias? É possível admitir que a distribuição de recursos seja direcionada, levando-se em consideração a batalha da falta de equidade que se materializa no acesso desigual a serviços de saúde e distribuição desigual entre grupos sociais? ${ }^{48}$

Para Organização Mundial da Saúde (OMS), procurar a equidade na saúde equivale a dizer que as políticas públicas e os sistemas públicos de saúde deveriam iniciar do princípio da existência de distinções nas condições sanitárias das pessoas e criar ações inclinadas a extinguir ou, pelo menos, diminuir ao mínimo possível as diferenças inúteis, evitáveis e injustas que existem entre grupos humanos com diferentes níveis sociais, disponibilizando ações e serviços de saúde em nome das necessidades. ${ }^{49}$

Como advoga o sociólogo e sanitarista francês Pierre Boitte, seria possível utilizar-se a noção de justiça como equidade de Rawls, impedindo os riscos da focalização, se a saúde fosse tratada como um dos bens sociais primordiais, de extrema relevância, equivalente às liberdades básicas, sob a orientação do princípio

\footnotetext{
$\overline{45}$ FONSECA, Márcio Alves da. Michel Foucalt e o Direito. 2. ed. São Paulo: Saraiva, 2012, p. 279.

${ }^{46}$ Ibid., p. 281-282.

${ }^{47}$ GRACIA, apud OGUISSO, Taka; ZOBOLI, Elma Lourdes Campos Pavone. Ética e bioética: desafios para a enfermagem e a saúde. Barueri: Manole, 2006, p. 191-192.

${ }^{48}$ OGUISSO, ibid., p. 192.

${ }^{49}$ Id.
} 
da universalidade de acesso aos cuidados de saúde. Após, numa segunda etapa, por meio do princípio da diferença, dar preferência aos recursos de saúde para as pessoas menos favorecidas, menos afortunadas. Logo, o princípio da diferença seria aplicado não às necessidades médicas, mas às necessidades sociais. ${ }^{50}$

Há limites para os direitos fundamentais, afinal não são absolutos. No confronto entre os direitos fundamentais, existem situações casuísticas que necessitam ponderação ou balanceamento, de forma a considerar o valor fundamental e peso inerente a cada bem jurídico envolvido, com prevalência de um deles ou de certa posição. A Constituição também permite a limitação de determinados direitos fundamentais ao estabelecer reservas legais. Também existe a possibilidade de restrições a direitos fundamentais se houver estado de defesa ou estado de sítio. Por fim, direitos fundamentais genericamente dispostos podem ser melhor definidos e conformados pelo legislador até para que possam ser exercidos. Assim, direitos fundamentais podem sofrer restrições, mas elas não devem chegar ao ponto de os tornar insubsistentes, pois não se pode atingir a proteção conferida pelo núcleo essencial dos direitos fundamentais.

O direito à saúde é um direito fundamental social disposto na Constituição de 1988, com dispositivo que estabelece a integral proteção, o que não significa que as pessoas têm o direito de requerer tratamentos inviáveis e sem qualquer comprovação científica de eficácia.

Por tal razão, a Lei 12.401/2011, de modo a estabelecer a proteção integral à saúde, definiu que a realização de procedimentos terapêuticos e o dispensar de medicamentos e produtos devem estar em conformidade com diretrizes terapêuticas definidas em protocolo clínico para a doença, com fundamental importância para o fato de que serão "avaliados quanto à sua eficácia, segurança, efetividade e custoefetividade para as diferentes fases evolutivas da doença ou do agravo à saúde". ${ }^{1}$ Ante a ausência de diretrizes terapêuticas, podem ser dispensados medicamentos constantes nas relações de remédios dos gestores federal, estadual ou municipal do SUS, porém sempre com a observância da vedação prevista no art. 19-T da referida legislação, que impede o pagamento, o ressarcimento ou o reembolso de medicamento, produto e procedimento clínico ou cirúrgico experimental, ou de uso

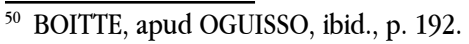

${ }^{51}$ BRASIL. Lei 12.401, de 28 de abril de 2011. Altera a Lei n 8.080, de 19 de setembro de 1990, para dispor sobre a assistência terapêutica e a incorporação de tecnologia em saúde no Âmbito do Sistema Único de Saúde SUS. Brasília, DF, DOU, 24 de abril de 2011. Disponível em: < http://www.planalto.gov.br/ccivil_03/_Ato20112014/2011/Lei/L12401.htm >. Acesso em: 10 ago. 2016.
} 
não autorizado pela Agência Nacional de Vigilância Sanitária (ANVISA), bem como a dispensação, o pagamento, o ressarcimento ou o reembolso de medicamento e produto, nacional ou importado, sem registro na ANVISA. ${ }^{52}$

Deve-se considerar o alto risco à saúde das pessoas na hipótese de fornecimento de tratamentos sem comprovação científica, de maneira que o fato de um cidadão requerer um medicamento não significa que poderá obtêlo, especialmente se o fármaco não estiver em conformidade com o protocolo terapêutico para a enfermidade ou, inexistente este, se o remédio não tiver eficácia comprovada para a doença.

As normas da Lei 12.401/2011 foram relevantes para o estabelecimento da chamada "Medicina Fundada em Evidências" (MFE), com um modelo segundo o qual órgãos do Sistema de Saúde devem realizar estudos para verificar se remédios e procedimentos são adequados para os tratamentos de pacientes e só então liberá-los para os consumidores.

No Brasil, ganhou corpo a Avaliação de Tecnologias em Saúde (ATS), realizada principalmente pela atividade da Comissão Nacional de Tecnologias no SUS (CONITEC), em face de consultas públicas, com muitas decisões sobre demandas de incorporação de produtos e serviços, com posterior submissão à ANVISA para a inclusão no rol de tratamentos.

A preocupação com a avaliação do emprego de novas tecnologias na área da saúde não é, todavia, exclusividade do nosso país, pois a ATS é objeto de agências criadas em outros países, com a mesma finalidade:

O último quarto do século XX testemunhou tanto a aceleração da dinâmica tecnológica em saúde quanto a explosão dos custos do cuidado à saúde, e foi durante a sua última década (e decorrente desses dois processos) que floresceram e se institucionalizaram as atividades de ATS. Dentre as atualmente atuantes, as primeiras agências a serem criadas com a missão de realizar ATS foram a da Suécia - Swedish Council on Health Technology Assessment, criada em 1987 (http://www.sbu.se/en), seguida da norte-americana Agency for Healthcare Research and Quality (http://www.ahrq.gov/), criada em 1999, em substituição a outra com missão similar, fundada uma década antes. A britânica NICE (National Institute for Health and Care Excellence) (http://www.nice.org.uk) foi fundada em 1999 e é, talvez, a mais reconhecida dentre as agências nacionais de ATS. Esse reconhecimento é, sem dúvida, conferido em grande parte pela importância do sistema público de saúde em seu país. Adiantando um

52 Loc. cit. 
tema que voltaremos a tratar mais adiante, o sucesso das agências depende em muito desse reconhecimento e prestígio públicos. $\mathrm{Na}$ Alemanha, o Institut für Qualität und Wirtschaftlichkeit im Gesundheitswesen (IQWiG) (https://www.iqwig.de/en/home.2724.html) foi criado em 2004. A agência francesa, Haute Autorité de Santé (www. has-sante.fr/) foi fundada também em 2004. No Canadá, em 2006 foi criada a Canadian Agency for Drugs and Technologies in Health (www.cadth.ca/), em substituição a outra agência existente desde 1990. Em 1993 foi criado o International Network of Agencies for HTA (INAHTA) (www.inahta.org/), que reúne as agências nacionais de ATS e em 2003 foi criada a Health Technological Assessment International (HTAi) (www.htai2014.org/), que congrega pesquisadores e operadores de ATS em todo o mundo. ${ }^{53}$

Contesta-se a limitação legal brasileira de impedir o fornecimento de medicamento não registrado na ANVISA, se houver a comprovação científica da efetividade, quando o remédio for ministrado no estrangeiro com o devido reconhecimento, pois o Sistema de Saúde brasileiro deve acompanhar o progresso havido em outros países. Consequentemente, ainda que o tratamento não seja registrado na ANVISA, caso haja comprovação da eficácia terapêutica por outras agências de saúde no mundo, ele deve ser fornecido.

\section{EXISTE UM DIREITO FUNDAMENTAL À AQUISIÇÃO DE FOSFOETANOLAMINA SINTÉTICA EM FACE DO ESTADO?}

Recentemente, iniciou-se um amplo e acalorado debate no cenário nacional a respeito da utilização do composto denominado fosfoetanolamina sintética, que ficou conhecido popularmente como "pílula do câncer", para tratamento e possível cura da doença. O debate acirrou-se no momento em que a substância parou de ser fornecida e pacientes que estavam fazendo seu uso começaram a propor demandas judiciais, com pedidos de liminares.

A análise do tema é importante, pois a substância não é considerada um medicamento, não está aprovada e registrada perante a ANVISA e ainda não foi reconhecida pelo Conselho Federal de Medicina, ou seja, é caracterizada como de caráter experimental, motivo pelo qual não se tem conhecimento da sua real eficácia ou dos seus efeitos colaterais, pelo menos não por parte dos órgãos governamentais oficiais.

$\overline{53}$ GUIMARÃES, Reinaldo. Incorporação tecnológica no SUS: o problema e seus desafios. Revista Ciência \& Saúde Coletiva. Manguinhos, RJ, v. 19, n. 12, p. 4899-4908, dez. 2014. Disponível em: < http://www.scielo.br/pdf/csc/ v19n12/pt_1413-8123-csc-19-12-04899.pdf>. Acesso em: 16 set. 2016. 
Em breve histórico, a fosfoetanolamina é um composto químico, isolado pela primeira vez em 1936 por Edgar Laurence Outhouse, do Departamento de Pesquisas Médicas do Instituto Banting da Universidade de Toronto, Canadá.

No início dos anos 90, Gilberto Orivaldo Chierice, que compunha o Instituto de Química de São Carlos da Universidade de São Paulo, começou a analisar a substância. A partir de efeitos iniciais promissores em alguns paradigmas experimentais em linhagens celulares de câncer e em animais, iniciou-se a administração em determinados pacientes acometidos da enfermidade na região de São Carlos, no Estado de São Paulo. ${ }^{54}$

Mesmo sem testes científicos em seres humanos, a substância foi entregue gratuitamente a pacientes com câncer por mais de 20 anos. ${ }^{55}$

Em junho de 2014, a Universidade de São Paulo (USP) cessou o fornecimento da substância e os pacientes começaram a propor ações judiciais, com pedido de liminares, para a obtenção do composto. A disputa chegou ao STF, que permitiu, momentaneamente, em outubro de 2015 , a produção e distribuição da fosfoetanolamina. Não obstante, desde novembro de 2015, em razão de uma nova decisão judicial, a disponibilização do composto restou proibida, tendo a polícia fechado um laboratório em Conchal, no Estado de São Paulo, que estava confeccionando de forma ilegal o produto. ${ }^{56}$

Em 16 de novembro de 2015, Celso Pansera, então Ministro da Ciência, Tecnologia e Inovação, divulgou a informação de que o Governo Federal pretendia adquirir 500 gramas da fosfoetanolamina sintética, e requereu ao Instituto Nacional de Propriedade Industrial (INPI) o teor da solicitação de patente da molécula, com o objetivo de dar sequência nos estudos para validar ou não os efeitos do produto, que pode vir a ser ministrado para tratamento do câncer. ${ }^{57}$

Em 25 de novembro de 2015, o ex-Ministro aprovou a liberação de dois milhões de reais para início das pesquisas acerca da eficácia e da segurança da fosfoetanolamina, valor repassado aos laboratórios credenciados para realizar os

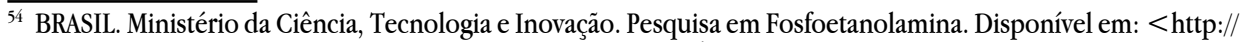
www.mcti.gov.br/fosfoetanolamina. > Acesso em: 29 mar. 16.

55 BRASIL. Sociedade Brasileira e Oncologia Clínica. Disponível em: < http://www.sboc.org.br/instituto-do-cancer-de-sp-coordenara-teste-em-humano-da-fosfoetanolamina/. > Acesso em: 16 set. 16.

${ }^{56}$ Id.

${ }^{57}$ BRASIL. Ministério da Ciência, Tecnologia e Inovação. Pesquisa em Fosfoeanolamina. Governo federal define passos para estudar fosfoetanolamina. Disponível em: <http://www.mcti.gov.br/fosfoetanolamina-noticias/-/ asset_publisher/tLKDj59Y36I/content/governo-federal-define-passos-para-estudar-fosfoetanolamina;jsessioni$\mathrm{d}=1 \overline{\mathrm{FA}} 5$ FCE989CEB77438FFC3F823C48D1A > . Acesso em: 29 mar. 2016.
} 
experimentos por meio do Conselho Nacional de Desenvolvimento Científico e Tecnológico (CNPq/MCTI).$^{58}$

Os testes começaram e, apesar de não haver constatação de sinal indicativo de toxidade, os relatórios iniciais elaborados e disponibilizados pelo Ministério da Ciência, Tecnologia e Inovação assim apontaram:

Os resultados indicaram que as cápsulas de FOSFOETANOLAMINA (FOS) provenientes do Instituto de Química de São Carlos da Universidade de São Paulo (IQSC-USP), encaminhadas pelo Ministério da Ciência, Tecnologia e Inovação (MCTI), contêm: 32,2\% de FOSFOETANOLAMINA (FOS) - (sendo ca. 6,2\% associada a íons metálicos); $18,2 \%$ de MONOETANOLAMINA PROTONADA (MEA.H+); $3,9 \%$ de FOSFOBISETANOLAMINA (FBEA); 34,9\% de fosfatos de cálcio, magnésio, ferro, manganês, alumínio, zinco e bário (Pi); 3,6\% de pirofosfatos de cálcio, magnésio, ferro, manganês, alumínio, zinco e bário (PPi); 7,2\% de água (H2O).

$[\ldots]$.

Os resultados descritos no relatório parcial demonstram que somente a Monoetanolamina apresentou atividade citotóxica e antiproliferativa, sendo contudo, várias ordens de magnitude menos potentes que os antitumorais Cisplatina e Gencitabina, utilizados como controle positivo. Já a Fosfoetanolamina e a Fosfobisetanolamina não apresentaram nenhuma atividade citotóxica nem antiproliferativa em nenhuma das metodologias utilizadas. ${ }^{59}$

A princípio, de acordo com o que se verifica no relatório das pesquisas iniciais, com base em testes elaborados pelo Centro de Inovação e Ensaios PréClínicos (CIEnP), solicitados pelo Ministério da Ciência, Tecnologia e Inovação (MCTI), parece que a fosfoetanolamina não é tão pura e nem tão eficiente contra células cancerígenas como afirmaram seus criadores.

O Professor Luiz Carlos Dias, coordenador do Laboratório de Química Orgânica Sintética (LQOS) do Instituto de Química (IQ) da Universidade de Campinas (UNICAMP), o qual ficou responsável por caracterizar e sintetizar cada componente das cápsulas de fosfoetanolamina, esclareceu que existia uma grande diferença de peso nas cápsulas da substância fornecidas originariamente pelo

\footnotetext{
58 BRASIL. Ministério da Ciência, Tecnologia e Inovação. Ministro sugere legalizar fosfoetanolamina como suplemento alimentar. Disponível em: < http://www.mcti.gov.br/fosfoetanolamina-noticias/-/asset publisher/ ltLKDj59Y36I/content/ministro-assina-contrato-de-liberacao-de-verbas-para-pesquisa-com-a-fosfoetanolamina >. Acesso em: 29 mar. 16.

59 BRASIL. Ministério da Ciência, Tecnologia e Inovação. Resumo Executivo - Relatórios Fosfoetanolamina. Disponível em: <http://www.mcti.gov.br/documents/10179/1274125/SUM\%C3\%81RIO+ATIVIDADES+FOS +\%E2\%80\%93\%20RELAT\%C3\%93RIOS + FOSFOETANOLAMINA_v17-03-2016.pdf/ff0e98d3-f6f7-46a48f7e-1ff5829c1f28>. Acesso em: 30 mar. 16. [p. 1-2].
} 
Instituto de Química de São Carlos, ligado à USP, onde o composto foi produzido, com uma variação de $233 \mathrm{mg}$ a $509 \mathrm{mg}$, além da existência de outros componentes, e não somente a fosfoetanolamina. ${ }^{60}$

Os testes também concluíram que a fosfoetanolamina não apresentou, em experimentos elaborados in vitro, atividade contra células tumorais. Já em relação à substância monoetanolamina, foi verificada uma pequena atividade, porém foi preciso utilizar uma concentração muito alta para conseguir atividade citotóxica e antiproliferativa, explicou Luiz Carlos Dias. Essa constatação, afirma ele, pode esclarecer porque os criadores da fosfoetanolamina sintética afirmam que o composto é ativo e a fosfoetanolamina adquirida comercialmente não tem a mesma propriedade, uma vez que esta última não possui monoetanolamina, a qual exerce uma diminuta ação antitumoral, mas de uma magnitude muito menos potente que os antitumorais cisplatina e gencitabina, utilizados como controle positivo. ${ }^{61}$

Em 30 de março de 2016, o ex-Ministro Celso Pansera, ao comentar os resultados iniciais das pesquisas com fosfoetanolamina, chegou a sugerir a legalização do produto como suplemento alimentar junto à ANVISA, para ser colocado à venda em farmácias e lojas especializadas. Para ele, a medida evitaria que famílias e pacientes buscassem fontes desconhecidas de produção e disponibilização do composto, com destaque para o fato de que os testes preliminares concluíram pela inexistência de toxidade na utilização da substância. ${ }^{62}$

A ANVISA, por meio de nota técnica, afirmou que não há pesquisa nos Estados Unidos, Europa ou Japão a respeito da fosfoetanolamina como alimento, suplemento ou medicamento. ${ }^{63}$

Mesmo em face de tais circunstâncias, conquanto os testes iniciais não tenham demonstrado resultados tão promissores quanto se esperava, o plenário do Senado Federal brasileiro aprovou, em 22 de março de 2016, Projeto de Lei da Câmara (PLC) que permite a pacientes com câncer fazerem uso da fosfoetanolamina sintética antes de seu registro na ANVISA. ${ }^{64}$ A Lei $13.269 / 2016$ passou a permitir

\footnotetext{
${ }^{60}$ UNIVERSIDADE ESTADUAL DE CAMPINAS (UNICAMP). Disponível em: < http://www.unicamp.br/unicamp/ noticias/2016/03/23/novos-dados-sobre-fosfoetanolamina > . Acesso em: 30 mar. 16.

${ }^{61}$ Loc. cit.

${ }^{62}$ BRASIL. Ministério da Ciência Tecnologia e Inovações e Comunicação. Ministro sugere legalizar fosfoetanolamina como suplemento alimentar. Disponível em: < http://www.mcti.gov.br/noticia/-/asset publisher/epbV0pr6eIS0/content/ministro-sugere-legalizar-fosfoetanolamina-como-suplemento-alimentar $>$. Acesso em: 30 mar. 2016.

${ }^{63}$ Id.

${ }^{64}$ UNIVERSIDADE ESTADUAL DE CAMPINAS (UNICAMP), loc. cit.
} 
a produção, a importação, a prescrição, a posse ou o uso da substância, mesmo sem registro, enquanto estiverem em andamento pesquisas clínicas a respeito da substância. ${ }^{65}$

O STF, por maioria de votos, ao apreciar pedido de liminar na Ação Direta de Inconstitucionalidade n. 5.501, proposta pela Associação Médica Brasileira (AMB), suspendeu a eficácia da Lei 13.269/2016 e, por consequência, o uso da fosfoetanolamina sintética. ${ }^{66}$

Permanece, não obstante, a controvérsia acerca da eficácia ou não da substância. Em uma outra pesquisa, realizada durante a elaboração de dissertação de mestrado na Universidade de São Paulo (USP), chegou-se à seguinte conclusão:

Comparando sua atividade inibitória "in vitro" a outros quimioterápicos, usualmente administrados em portadores de cânceres, como o paclitaxel, inibidor específico na fase G2/M ou o estoposideo, inibidor de topoisomerases tipo II, a fostoetanolamina sintética se mostrou cerca de 130 vezes mais eficaz em sua atividade inibitória que as drogas comerciais, demonstrados neste mesmo estudo. ${ }^{67}$

De toda forma, por ser a vida tão essencial, ante toda essa controvérsia em torno da eficácia da fosfoetanolamina, não se poderia mesmo esperar uma ação estatal uniforme quanto ao fornecimento ou não do composto para pacientes com câncer.

A existência de lei a autorizar a disponibilidade da substância, mesmo antes de seu registro perante a ANVISA, demonstra haver uma preocupação com a saúde daqueles que já vinham fazendo uso da fosfoetanolamina há algum tempo, os quais afirmavam perceber melhoras significativas em suas patologias.

Sob este aspecto, a atitude do Congresso Nacional foi louvável e não pode

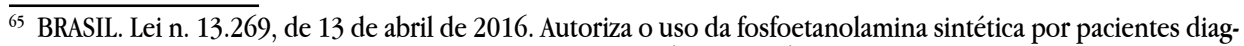
nosticados com neoplasia maligna. Brasília, DF, DOU, 14 abr. 2016. Disponível em: < http://www.planalto. gov.br/ccivil_03/_Ato2015-2018/2016/Lei/L13269.htm >. Acesso em: 17 jul. 2016.

${ }^{66}$ BRASIL. Supremo Tribunal Federal. Ação Direta de Inconstitucionalidade n. 5.501/DF. Requerente: Associação Médica Brasileira. Relator: Ministro Marco Aurélio. Plenário. Brasília, DF, 19 de maio de 2016. Decisão: O Tribunal, por maioria e nos termos do voto do Relator, deferiu a liminar para suspender a eficácia da Lei $\mathrm{n}^{\circ}$ 13.269/2016, até o julgamento final desta ação, vencidos, em parte, os Ministros Edson Fachin, Rosa Weber, Dias Toffoli e Gilmar Mendes, que concediam a liminar para dar interpretação conforme. Falou pela requerente Associação Médica Brasileira o Dr. Carlos Magno Michaelis Júnior. Ausente, justificadamente, o Ministro Celso de Mello. Presidiu o julgamento o Ministro Ricardo Lewandowski. Disponível em: < http://www.stf.jus. $\mathrm{br} /$ portal/processo/verProcessoAndamento.asp?incidente $=4966501>$. Acesso em: 17 jul. 2016 .

${ }^{67}$ MENEGUELO, Renato. Efeitos antiproliferativos e apoptóticos da fosfoetanolamina sintética no melanoma B16F10. 2007. 132 f.. Dissertação (Mestrado em Bioengenharia). Universidade de São Paulo, São Carlos, 2007. Disponível em: $\quad<$ http://www.teses.usp.br/teses/disponiveis/82/82131/tde-12022008-135651/pt-br.php>. Acesso em: 31 mar. 2016. [p. 106-107]. (g.n.) 
deixar de ser destacada, mas o problema persiste, porquanto, apesar da autorização da disponibilização da fosfoetanolamina antes do seu registro na ANVISA, a substância ainda é considerada oficialmente experimental, pelo menos do ponto de vista dos órgãos governamentais e do Conselho Federal de Medicina.

Ainda existem poucos dados publicados, a exemplo da dissertação de mestrado mencionada anteriormente, apenas referentes a testes realizados em animais. Não há publicações científicas que evidenciem a realização de pesquisas de acordo com os protocolos determinados por órgãos oficiais.

Por tal razão, mostra-se também compreensível a decisão adotada no STF acerca da suspensão da eficácia da lei em face das consequências da liberação do composto químico.

$O$ fato de ainda ser considerada experimental significa que não se tem conhecimento dos reais benefícios que a substância pode apresentar ou de sua verdadeira eficácia, razão pela qual também são desconhecidos os seus verdadeiros efeitos colaterais, e que também podem existir, apesar de nada ter sido descoberto até agora a respeito. Isso não que dizer que os depoimentos de várias pessoas, que afirmam ter obtido bons resultados com o uso do produto, devam ser desconsiderados. Pode ser que, realmente, num futuro próximo, conclua-se pela eficácia da fosfoetanolamina para a cura do câncer, mas, até o momento, os órgãos oficiais não chegaram a esta conclusão.

Restam importantes questionamentos. Considerando que determinada substância ou medicamento possui caráter experimental, mesmo nesta condição o direito de aquisição deste produto poderia ser considerado fundamental de acordo com a previsão constitucional de acesso universal aos meios de preservação e recuperação da saúde? Estaria o Estado obrigado a fornecer uma droga ou um composto que ainda não foi devidamente reconhecido como eficaz pela Medicina e aprovado pela ANVISA?

Estas perguntas não permitem respostas simples. Alguns fatores importantes devem ser considerados.

A saúde, sob o aspecto da preservação e recuperação por meio de medicamentos, é direito fundamental e também da personalidade. Não há dúvida a respeito, todavia nem a Constituição Federal ou qualquer outra norma do ordenamento jurídico brasileiro garante a cobertura de substâncias ou medicamentos considerados experimentais. Deve-se isso ao fato de que a utilização de fármacos ou 
produtos ainda não reconhecidos pela Medicina para tratamento de determinadas patologias pode implicar risco para a própria saúde do paciente, inclusive colocando em perigo a preservação da vida.

É importante destacar, tanto o direito fundamental à saúde como os demais direitos considerados fundamentais não são absolutos. Eles podem sofrer restrições ou limitações, sendo estas legais ou fáticas. Uma das limitações legais é justamente a proibição de comercialização de medicamentos considerados experimentais. Por outro lado, pode-se verificar uma limitação fática quando se constata a escassez de recursos suficientes para atender a todos que buscam acesso aos meios de saúde, considerando que, para todo Direito, existe um custo.

A disponibilização, por parte do Estado, de medicamentos ou substâncias ainda não reconhecidos pela Medicina ou aprovados pela ANVISA, a exemplo da fosfoetanolamina, extrapola os limites e restrições a que se submetem os direitos fundamentais, como é o caso do direito fundamental à saúde, que se concretiza por meio da distribuição gratuita de medicamentos para tratamento do câncer ou outras doenças.

Como os recursos na área de saúde não são ilimitados e este setor no Brasil já vem sofrendo em razão desta escassez, a permissão para produção imediata da fosfoetanolamina, sem a correspondente aprovação por parte dos órgãos competentes, implicaria elevação dos custos para atender as demais demandas, onerando ainda mais o Estado, dependente da arrecadação de impostos para alcançar suas metas e programas. A arrecadação atual tem-se mostrado, ou ao menos aparentado ser, insuficiente.

Portanto, apesar de algumas reportagens recentes anunciarem que vários pacientes tiveram resultados positivos com o uso da fosfoetanolamina e o Congresso ter aprovado uma lei que autoriza a disponibilização da substância, pode-se afirmar que não existe um direito fundamental à aquisição desta substância em face do Estado, ainda que seja a título de suplemento alimentar, antes que todos os testes sejam realizados e o produto tenha a sua eficácia demonstrada para, finalmente, ser aprovado pelo órgão responsável e incluída no orçamento público a previsão dos custos de produção e distribuição. O Poder Público não está obrigado, seja pela Constituição Federal ou por qualquer norma infraconstitucional, a fornecer e custear a fosfoetanolamina antes do seu registro. 


\section{CONSIDERAÇÕES FINAIS}

A saúde é um direito fundamental atrelado à dignidade da pessoa humana, integrante do direito ao mínimo para uma vida digna e a proteção a este direito impacta no desenvolvimento da personalidade humana.

Em razão de seu caráter fundamental, ela foi inserida na Constituição Federal brasileira e passou a ter o Estado como seu maior garantidor, o qual ficou responsável por assegurar o seu acesso de maneira universal e igualitária.

Apesar da proteção que lhe é devida, constatou-se que, no Brasil, ela não vem recebendo o tratamento adequado por parte dos entes públicos, fato notório, em razão da má qualidade na prestação dos serviços de saúde, das grandes filas de espera para atendimento e da ausência de recursos materiais suficientes para atender a todos que necessitam de alcance aos meios de acesso a ela.

Verificou-se que os direitos fundamentais podem sofrer limitações, uma vez que não são absolutos; e os recursos, especialmente os destinados à concretização de prestações positivas, não são infinitos, mas escassos.

A própria Organização Mundial da Saúde admitiu que não há possibilidade de disponibilizar a todos a integralidade de eventos na saúde, razão pela qual sempre se faz necessário sejam estabelecidas prioridades no estabelecimento e destinação de recursos.

A aquisição de medicamentos para tratamento de doenças, como o câncer, também é um direito fundamental e o Estado tem o dever constitucional de disponibilizar gratuitamente todos os fármacos, reconhecidos pela medicina e registrados perante a ANVISA, capazes de atuar na recuperação de patologias.

Quanto à eficácia da fosfoetanolamina sintética para tratamento do câncer, existem poucos dados publicados, a exemplo da dissertação de mestrado mencionada neste artigo, mas apenas referentes a testes realizados em animais. Não há publicações científicas que evidenciem a realização de pesquisas de acordo com os protocolos determinados por órgãos oficiais.

Apesar da divulgação de depoimentos pessoais na mídia, atestando a eficácia da fosfoetanolamina no tratamento do câncer, a referida substância ainda não foi reconhecida pela Medicina e nem aprovada pela ANVISA, razão pela qual permanece sendo considerada de caráter experimental.

Em razão disso, conclui-se, com este artigo, que não existe um direito fundamental à aquisição de fosfoetanolamina em face do Estado, ainda que seja a 
título de suplemento alimentar, uma vez que esta substância ainda não se submeteu a todos os testes necessários por parte do órgão responsável pelo registro, existem poucos estudos, realizados apenas em animais, bem como ainda não se tem conhecimento de sua real eficácia na cura do câncer e dos possíveis efeitos colaterais.

\section{REFERÊNCIAS}

BARCELLOS, Ana Paula. Eficácia jurídica dos princípios constitucionais: o princípio da dignidade da pessoa humana. 3. ed. Rio de Janeiro: Renovar, 2011.

BARROSO, Luís Roberto. A dignidade da pessoa humana no direito constitucional contemporâneo: a construção de um conceito à luz da jurisprudência mundial. Tradução de Humberto Laport de Mello. Belo Horizonte: Fórum, 2014.

BITENCOURT, Eurico Neto. O direito ao mínimo para uma existência digna. Porto Alegre: Livraria do Advogado, 2010.

BONAVIDES, Paulo. Curso de Direito Constitucional. 29. ed. São Paulo: Malheiros, 2014.

BRASIL. Conselho Nacional de Justiça. Notícias. Brasil tem mais de 240 mil processos na área da saúde. < http://www.cnj.jus.br/noticias/cnj/56636-brasil-tem-mais-de-240mil-processos-na-area-de-saude > . Acesso em: 12 jan. 2016.

BRASIL. Constituição (1988). Constituição da República Federativa do Brasil: promulgada em 5 de outubro de 1988. São Paulo: Saraiva, 2014.

BRASIL. Lei n. 13.269, de 13 de abril de 2016. Autoriza o uso da fosfoetanolamina sintética por pacientes diagnosticados com neoplasia maligna. Brasília, DF, DOU, 14 abr. 2016. Disponível em: <http://www.planalto.gov.br/ccivil_03/_Ato20152018/2016/Lei/L13269.htm> . Acesso em: 17 jul. 2016.

BRASIL. Ministério da Ciência, Tecnologia e Inovação. Pesquisa em Fosfoetanolamina. Disponível em: < http://www.mcti.gov.br/fosfoetanolamina $>$. Acesso em: 29 mar. 16. 
BRASIL.MinistériodaCiência,TecnologiaeInovação.Pesquisa emFosfoetanolamina. Governo define passos para estudar fosfoetanolamina. Disponível em: $<$ http://www. mcti.gov.br/fosfoetanolamina-noticias/-/asset_publisher/ltLKDj59Y36I/content/ governo-federal-define-passos-para-estudar-fosfoetanolamina;jsessionid=1FA5FCE 989CEB77438FFC3F823C48D1A > . Acesso em: 29 mar. 2016.

BRASIL. Ministério da Ciência, Tecnologia e Inovação. Pesquisa em Fosfoetanolamina. Ministro assina contrato de liberação de verbas para pesquisa com a fosfoetanolamina. Disponível em: < http://www.mcti.gov.br/fosfoetanolaminanoticias/-/asset_publisher/ltLKDj59Y36I/content/ministro-assina-contrato-deliberacao-de-verbas-para-pesquisa-com-a-fosfoetanolamina. $>$. Acesso em: 29 mar. 16 .

BRASIL. Ministério da Ciência, Tecnologia e Inovação. Resumo Executivo: Relatórios Fosfoetanolamina. Disponível em: $<$ http://www.mcti.gov.br/documents/10179/1274125/ S U M \% C $3 \% 81$ R I O + AT IVID A D E S + F O S + \% E $2 \% 80 \% 93 \% 20$ RELAT\%C3\%93RIOS + FOSFOETANOLAMINA_v17-03-2016.pdf/ff0e98d3-f6f7-46a48f7e-1ff5829c1f28. > . Acesso em: 30 mar. 2016.

BRASIL. Ministério da Ciência, Tecnologia, Inovações e Comunicação. Ministro sugere legalizar fosfoetanolamina como suplemento alimentar. Disponível em: $<$ http://www.mcti.gov.br/noticia/-/asset_publisher/epbV0pr6eIS0/content/ministrosugere-legalizar-fosfoetanolamina-como-suplemento-alimentar $>$. Acesso em: 30 mar. 2016.

BRASIL. Sociedade Brasileira de Oncologia Clínica. Disponível em: <http:// www.sboc.org.br/instituto-do-cancer-de-sp-coordenara-teste-em-humano-dafosfoetanolamina/. > . Acesso em: 17 set. 16.

BRASIL. Supremo Tribunal Federal. Ação Direta de Inconstitucionalidade n. 5.501/DF. Requerente: Associação Médica Brasileira. Relator: Ministro Marco Aurélio. Plenário. Brasília, DF, 19 de maio de 2016. Plenário, 19.05.2016. Disponível em: < http:// www.stf.jus.br/portal/processo/verProcessoAndamento.asp?incidente $=4966501>$. Acesso em: 17 jul. 2016. 
CARLINI, Angélica Lúcia. Judicialização da saúde pública no Brasil. In: CARNEIRO, Luiz Augusto Ferreira (Coord.). Planos de saúde: aspectos jurídicos e econômicos. Rio de Janeiro: Forense, Gen, IESS, 2012.

COMPARATO, Fábio Konder. A afirmação histórica dos direitos humanos. 9. ed. São Paulo: Saraiva, 2015.

DALLARI, Dalmo de Abreu. Direitos humanos e cidadania. 2. ed. São Paulo: Moderna, 2004.

ESTADOS UNIDOS. Declaração de Direitos do Bom Povo de Virgínia. Universidade de São Paulo - USP. Biblioteca virtual de direitos humanos. Disponível em: $<$ http://www.direitoshumanos.usp.br/index.php/Documentos-anteriores-\%C3\%A0cria\%C3\%A7\%C3\%A3o-da-Sociedade-das-Na\%C3\%A7\%C3\%B5es-at\%C3\%A9-1919/ declaracao-de-direitos-do-bom-povo-de-virginia-1776.html.> Acesso em: 14 jan. 2016.

FERRAZ, Marcos Bosi. Economia da saúde e sua inserção no sistema da saúde. In: BLIACHERIENE, Ana Carla; SANTOS, José Sebastião dos (Org.). Direito à vida e à saúde: impactos orçamentários e judicial. São Paulo: Atlas, 2010.

FOLLAND, Sherman; GOODMAN, Allen C.; STANO, Miron. A economia da saúde. Tradução de Cristina Bazan. 5. ed. Porto Alegre: Bookman, 2008.

FONSECA, Márcio Alves da. Michel Foucalt e o Direito. 2. ed. São Paulo: Saraiva, 2012.

FREITAS, Luiz Fernando Calil. Direitos fundamentais: limites e restrições. Porto Alegre: Livraria do Advogado, 2007.

MENEGUELO, Renato. Efeitosantiproliferativoseapoptóticos dafosoetanolamina sintética no melanoma B16F10. 2007. 132f. Dissertação (Mestrado em Bioengenharia). Universidade de São Paulo, São Carlos, 2007. Disponível em: $<$ http://www.teses.usp.br/teses/disponiveis/82/82131/tde-12022008-135651/pt-br. php>. Acesso em: 31 mar. 2016

MIRANDA, Jorge. Manual de Direito Constitucional: direitos fundamentais. 5. ed. Coimbra: Coimbra, 2014, tomo IV. 
MORAES, Maria Celina Bodin de. O conceito de dignidade humana: substrato axiológico e conteúdo normativo. In: SARLET, Ingo Wolfgang (Org.). Constituição, direitos fundamentais e direito privado. 3. ed. Porto Alegre: Livraria do Advogado, 2010 .

OGUISSO, Taka; ZOBOLI, Elma Lourdes Campos Pavone. Ética e bioética: desafios para a enfermagem e a saúde. Barueri: Manole, 2006.

ORGANIZAÇÃO DAS NAÇÕES UNIDAS (ONU). Assembleia-Geral das Nações Unidas. Pacto Internacional sobre os Direitos Econômicos, Sociais e Culturais. Nova York, em 19 de dezembro de 1966. Resolução no 2200-A (XXI). Disponível em: $<$ http://pfdc.pgr.mpf.gov.br/atuacao-e-conteudos-de-apoio/legislacao/direitoshumanos/pacto_int_dir_econ_sociais-culturais.pdf > . Acesso em: 19 set. 2016.

OTERO, Cleber Sanfelici. Inclusão social da extrema pobreza: direito à cidadania integral e contextualização do mínimo necessário no Brasil. 2011. 444f. Tese (Doutorado em Direito) - Instituição Toledo de Ensino de Bauru, Bauru.

PASOLD, Cesar Luiz. Direito à Saúde. Universidade Federal de Santa Catarina. Disponível em: <https://periodicos.ufsc.br/index.php/sequencia/article/ view/16398/14978> . Acesso em: 11 ago. 15.

PÉREZ LUÑO, Antonio Henrique. Los derechos fundamentales: temas clave de la Constituición española. 11. ed. Madrid: Tecnos, 2013.

ROCHA, Juan Stuardo Yazlle. População e serviços de saúde: as necessidades, demanda e utilização de serviços. In: ROCHA, Juan Stuardo Yazlle. Manual de saúde pública \& saúde coletiva no Brasil. São Paulo: Atheneu, 2012.

RODRIGUES, Okçana Yuri Bueno; OTERO, Cleber Sanfelici. Comentários a acórdão do Supremo Tribbunal Federal em Agravo Regimental que manteve tutela antecipada concessória de medicamentos em nome da preservação do direito à saúde. Revista Jurídica Cesumar - Mestrado. Maringá, PR, v. 13, n. 2 , p. 743-759, jul./dez. 2013. Disponível em: < http://periodicos.unicesumar.edu.br/index.php/revjuridica/article/ view/3099/2147>. Acesso em: 19 set. 2016.

SARLET, Ingo Wolfgang. A eficácia dos direitos fundamentais: uma teoria geral dos direitos fundamentais na perspectiva constitucional. 12. ed. Porto Alegre: Livraria do Advogado, 2015. 
SARLET, Ingo Wolfgang. Algumas considerações entorno do conteúdo, eficácia e efetividade do direito à saúde na constituição de 1988. Revista Diálogo Jurídico, n. 10, jan. 2002. Disponível em: < http://www.direitopublico.com.br > . Acesso em: 28 jan. 16.

SILVA, Diogo Bacha e; GONÇALVES, Luciano Meni. Judicialização da saúde e a transferência do controle sobre o corpo. Revista Jurídica Cesumar - Mestrado. Maringá, PR, v. 13, n. 2, p. 561-579, jul./dez. 2013. Disponível em: < http://periodicos. unicesumar.edu.br/index.php/revjuridica/article/view/3047/2139>. Acesso em: 19 set. 2016.

SILVA, Marcelo Gurgel Carlos da. Econômica da saúde: da epidemiologia à tomada de decisão. In: ROUQUAYROL, Maria Zélia; SILVA, Marcelo Gurgel Carlos da (Org.). Epidemiologia \& Saúde. 7. ed. Rio de Janeiro: MedBook, 2013

SOUZA, Sérgio Iglesias Nunes. Responsabilidade civil por danos à personalidade. Barueri, SP: Manole, 2002.

SZANIAWSKI, Elimar. Direitos de personalidade e sua tutela. 2. ed. São Paulo: Revista dos Tribunais, 2005.

UNIVERSIDADE ESTADUALDE CAMPINAS (UNICAMP). Disponível em: < http://www. unicamp.br/unicamp/noticias/2016/03/23/novos-dados-sobre-fosfoetanolamina $>$. Acesso em: 30 mar. 16.

Recebido em: 19 de setembro de 2016 Aceito em: 21 de novembro de 2016 